\title{
Understanding Continuous Citizen Participation on a Green Commuting Platform: The Roles of Public Value and Private Value
}

\author{
Jingrui Ju \\ Harbin Institute of Technology \\ jirrui@sina.cn
}

\author{
Luning Liu \\ Harbin Institute of Technology \\ liuluning@hit.edu.cn
}

\author{
Yuqiang Feng \\ Harbin Institute of Technology \\ fengyq@hit.edu.cn
}

\begin{abstract}
Citizen participation in IT-enabled social activity is an exchange between creating public value for others and gaining private value offered by public sectors in the perspective of social exchange theory. Prior literatures mostly focused on offline social activities and examined only the effects of participation antecedents on final participation outcomes, not investigating the potential participation mechanism in particular of the roles of public and private values. Thus, this study develops a theoretical model based on theories and incentives of citizen participation to examine what and how antecedents affect continuous citizen participation through public value creation and private value acquisition. With analyzing the survey data in the case of a Green Commuting platform, we identify the effective antecedents and find that private value acquisition has much greater effect on participation than public value creation and two values significantly mediate the effects of antecedents on participation.
\end{abstract}

\section{Introduction}

Citizen participation in co-creating public value is a new collaborative governance model, which contributes the efficiency improvement of public sectors, the promotion of citizens' satisfaction, and the increase of social benefits $[3,4,32,33,56]$. Public value creation is one of the main goals that drive the digitization of public sector organizations. IT-enabled innovations have been increasingly undertaken by public organizations to internally and externally allocate resources and capabilities in order to satisfy citizens' expectations and further encourage continuous their participation.

Research on citizen participation in political activities started early and gained more attention. Many participation theories and models were proposed in the long research history [12,15,34,35]. Recently, IT-enabled political participation has been innovated, such as E-voting, E-democracy, and online policy deliberation forums. The Singapore's REACH (www.reach.gov.sg) and the United States' eRulemaking program (www.regulations.gov) are two examples of online policy deliberation forums. In this new context, participation theories and models were rebuilt and developed with the addition of IT-enabled factors $[8,9,50]$. Apart from political participation, citizens also take part in some social activities, such as donation, volunteer service, and environment protection [26,37]. These activities have also been digitalized in recent years. For example, the See-ClickFix, a web-based service designed to help citizens report non-emergence issues in their neighborhood to local government, improves the respond speed of public sectors and enhances the trust between citizens and government [28]. Although some participation antecedents have been identified in the cases of offline social activities [26,36,37], research in the context of IT-enabled social activities is still in its infancy. Considerable differences exist between political and social participation: the former is usually associated with participants' political career, whereas the latter is not; the former places a higher demand on the personal skills of participants, whereas the latter is not. Therefore, research on the IT-enabled political participation could only provide an effective reference. Further research needs to be conducted to understand what factors influence citizen participation in ITenabled social activities.

Citizen participation could create many kinds of values, including the values for public organizations (e.g., improvement of efficiency and effectiveness), the values for citizens (e.g., satisfaction, empowerment, personal benefits), and the values for the society (e.g., democratic governance) [55]. From the point of citizen, these values can be divided into two categories: public value, which is beneficial for other stakeholders, and private value, which is beneficial for their own. Actually, certain cost of co-creating public value silently shift from government to citizens. Citizens' efforts on creating public value are viewed as the cost encountered by citizens. According to the social 
exchange theory, it is necessary for public sectors to meet citizens' needs if they expect continuous citizen participation in co-creating public value (e.g., cooperation and compliance) [7]. Therefore, the nature of citizen participation is a social exchange between paying efforts to co-create public value and gaining individual benefits offered by public sector. However, there is still a lack of knowledge on how public value and private value influence the participation process, which needs more empirical examination.

Thus, we aimed to address the two questions: what antecedents affect citizen participation in IT-enabled social activities and how public and private values influence the relationships between them. The case of a Green Commuting platform is selected to answer these questions. It is an IT application to quantify and encourage citizen participation in green commuting activity. Based on citizen participation theories, typical incentive models, and IT-enabled incentives, we developed a research model to investigate what and how various antecedents influence continuous citizen participation on the Green Commuting platform through public or private values. Survey data were collected from a government-sponsored Green Commuting platform. By developing and validating the model, this research contributes to both research and practice in this area.

\section{Theoretical background and hypotheses 2.1. Public value and private value of citizen participation: from the perspective of social exchange}

The concept of public value introduced by Mark Moore guided the strategic management of public sectors using public value in the similar way that private sectors view private value as strategic purpose $[1,2]$. Instead of economic value, public management actions emphasize public values of efficiency and fairness [1]. During the last decades, citizen participation has played an increasingly important role in co-creating public value with public sectors as public management transformed from traditional bureaucratic management to current collaborative governance $[3,4]$. Co-creation is a way to redefine the roles of government and citizens [55]. Citizens probably act as a co-implementer, a co-designer, or an initiator and their cooperation is helpful to reduce the cost of public value creation paid by the government [5]. Actually, the reduced cost is not eliminated but shifted from paid governmental employees to citizens.

In the perspective of social exchange theory, public sectors need things from citizens in particular of cooperation and compliance that are crucial for public value co-creation; eliciting those things necessitates meeting not only citizens' material needs but also their symbolic ones [7]. Therefore, public sectors implement various measures to compensate citizens and encourage their continuous contribution, such as material rewards, monetary rewards, tax breaks and social reputation or image [26,37]. It has also been noted that the production of public goods necessitates the provision of private incentives for citizens; else people may free ride [16]. Literatures also showed that citizens co-creation could not only create instrumental value for public organizations in terms of improving efficiency, effectiveness, and innovation [56], but also create instrumental value for citizens in terms of satisfaction, need fulfillment, and empowerment [32]. To some extent participation as a rational activity for citizens aims to maximize the benefits while minimizing the costs [6]. The citizen-government cocreation can be viewed as a social exchange for citizens between co-creating public value with public sector and gaining private value offered by public sector. Although citizens participating in collective activities is seen as value co-creation for public organizations or even social benefits co-production for the community, it is a cost for themselves. Fortunately, in most cases of collective coproduction, the goal is to produce social benefits, which are likely to create personal benefits for individuals [33].

\subsection{Citizen participation models and incentives}

Many theories and models of citizen participation have been developed to explain what and how factors and forces derive individual participation, especially in the contexts of political activities, including the standard political participation model [35], the social capital theory of participation [15], and the civic voluntarism model (CVM) [12,34]. Especially, the CVM, viewed as the most comprehensive model due to the inclusion of three broad classes of participation factors, i.e., motivations, resources, and mobilization, respectively derived from the general incentives model [13], resource-mobilization theory [14], and social capital theory of participation [15]. Specifically, motivations refer to benefits that incline citizens to participate. Resources include time, money, and civic skills that provide the means and ability to participate. Mobilization refers to the recruitment by friends and associates in one's interpersonal networks to participate in common networks built in places of worship, voluntary organizations, and work setting.

With the increasing diversity of incentives taken by public sector, the dimension of motivation was extended with the reference of general incentives model [8,9]. Specifically, it consists of collective incentives, selective incentives, group and expressive 
incentives, and social-norms-derived incentives [13]. Specifically, collective incentives are socially oriented benefits enjoyed by all members of the community regardless of whether they participate. Selective incentives are privatized outcomes from participation that fulfill individuals' self-interest, which can help solve the issue of free ride. Group and expressive incentives are related to individuals' confidence in and affection toward a group. Social-norms-derived incentives refer to the motivation to conform to others' influence to participate. Additionally, with the growing use of IT, public sectors digitally innovated means of public service delivery to satisfy citizen expectations and increase their participation in public value creation [38, 39,40]. The study of citizen participation has transformed into e-participation with the consideration of IT-enabled factors. IT-enabled resources on participation, like technological skill, connectivity or community, have been integrated into traditional participation model in some cases such as online policy deliberation forums and E-democracy [8,9,50].

Along with the extension of participation scope from general political activities to social ones, the CVM was also applied to study citizen behavior in social activities. Some self-interest motivation factors associated with citizen prosocial behavior were proposed and examined. For example, in the cases of donation and volunteer service, the effects of monetary incentives on citizen participation were most highly discussed but usually concluded inconsistent results [26,37]. Besides, image incentive or social reputation as non-monetary factor was also studied [26,36]. Similar with political activities, these social activities have begun digital innovation by using IT-enabled resources. Thus, more studies are needed to advance our understanding of how IT-enabled resources promote citizen participation in social activities, which is still be considered as nascent as a result of missing empirical evidence.

\subsection{Research model and hypotheses}

The above literatures reveal that gaps exists as to what and how factors influence citizen participation in digital social activities and what roles played by public value and private value during participation. Recently, public sectors not only internally digitalized but also increase their external abilities by using technology, for example through social networks and platformbased architectures [41]. The Green Commuting platform discussed in this study does not completely belong to the internal innovation of a specific public transportation department, but an online channel built by local government to support participatory social activity. Citizen participation in the platform not only facilitates the increasement of social collective benefits in the terms of urban traffic and environment, but also helps to obtain individual benefits from various platform incentives. We employ the CVM and the general incentives model as the primary theoretical foundation as well as consider related IT-enabled incentives to build a comprehensive theoretical model.

Researches on individual-level antecedents of participation have been carried out to provide new insights to public sectors for the improvement of citizen participation. However, participation decision is a rational value-oriented choice for citizens. It is necessary to balance the incurring cost for creating public value and the private benefit of government incentives. Previous studies only examined the direct effects of antecedents on final outcomes of citizen participation, such as participation intention, participation quality, and participation quantity $[8,9,10,11]$, not distinguishing their driving forces on values in different orientations in particular of value creation and value acquisition. It is acknowledged that values are important for understanding various social psychological phenomena and overt behavior is a particularly important potential consequence of value $[22,23]$. Personal engagement has three antecedents: value congruence, perceived support, and core selfevaluation and it is maintained while participants are physically, cognitively, and/or emotionally engaged in a chosen activity/task [53,54]. Participation on the Green Commuting platform makes it possible to simultaneously create public value and gain private value. These two values satisfy both rational cognitive needs and non-rational emotional needs, which is benefit for maintaining continuous citizen participation. Thus, we hypothesized that:

Hypothesis 1: Public value creation is positively related to continuous citizen participation on the Green Commuting platform.

Hypothesis 2: Private value acquisition is positively related to continuous citizen participation on the Green Commuting platform.

To further understand the roles of public and private value, this study focuses on the effects of antecedents of citizen participation on their associated values. Resource is the first dimension of the CVM. Though resources include time, money, and civic skills, most literatures associated with political participation emphasized the importance of civil skills [8,9,50]. They pointed out that money and time cannot adequate to translate to effective civic participation, while civil skills necessaries effective participation [42,50]. The reason is that political participation needs a certain level of communication and organizational skills. However, participation on the Green Commuting platform is very different from common political 
participation, not requiring any specific personal skills. Citizen only needs to proactively collect green points as rewards on the platform after taking public transportation offline. In this case, abundant time becomes a more important resource required for citizens than money and civil skills, which is proved by three reasons: taking public transportation usually takes more time than driving private cares or taking a taxi; Green commuting is often the least expensive way than any other tools; Citizens do not need any professional skills to participate in green commuting both online and offline. Time abundance is necessary when citizens physically take transportation to create public value as well as proactively collect green points as individual benefits online. Thus, we hypothesized that:

Hypothesis 3a: Time abundance is positively related to citizens' public value creation when they participate on the Green Commuting platform.

Hypothesis 3b: Time abundance is positively related to citizens' private value acquisition when they participate on the Green Commuting platform.

Social activities are always challenged by the problem of collective action. Many researchers have documented the effect of social network on citizen participation [43,45]. They figured out that the connections among people in a horizontally integrated community network could help to mobilize citizens to participate in social activities. These networks provide opportunities for individuals to proactively present personal behavior and passively be observed by others. It is acknowledged that green commuting taken in the real world is a physical action to create public value, which is public and probably observed by participant's friends or families. Additionally, the Green Commuting platform also provides individual leaderboard that quantifies citizens' efforts on green commuting, which contributes to the establishment of personal social image among all participants. Thus, we hypothesized that:

Hypothesis 4a: Mobilization is positively related to citizens' public value creation when they participate on the Green Commuting platform.

Hypothesis 4b: Mobilization is positively related to citizens' private value acquisition when they participate on the Green Commuting platform.

Motivation in the CVM consists of benefits for individuals and groups. It was extended with the reference of the general incentives model and examined by the case of online policy deliberation forums [8,9]. Here, we extended motivation in the same way. Collective incentives are firstly reconsidered. Some studies revealed the negative effect of collective incentives on the quantity of citizen participation in political activities $[8,46]$. They indicated that individuals tend to be more thoughtful and reduce their postings (i.e., political views or suggestions) when they understand that some postings containing repeated ideas or excluding a clear purpose may result in confusion or distraction for other participants. However, the social benefits generated from social activities (e.g., green commuting, blood donation, and voluntary services) are different from those generated from political activities. Every citizen participation in a social activity, like green commuting, could increase social benefits, but participation in a political activity may produce a positive or negative effect on the increasement of social benefits. Therefore, in contrast to political participation, we argue that citizens would be positively motivated by the collective incentives to make efforts on green commuting. As collective incentives are social, not personal ones, they could derive the creation of public value, not the acquisition of private value. Thus, we hypothesized that:

Hypothesis 5: Collective incentives are positively related to citizens' public value creation when they participate on the Green Commuting platform.

Selective incentives perceived as self-interests, a kind of private value, personally affects individuals to participate [13]. These incentives are usually contextualized by the specific context. For example, the effects of some selective incentives on citizen participation, such as political career benefit, persuasion benefit, political interest, and political involvement, have been examined in the context of political activities [8,50]. Green commuting is beneficial for health as the study revealed that active commuting (e.g., walking and cycling) could generate the 4 MJ weekly volume of physical activity commonly associated with enhanced health [47]. Therefore, health benefits will be a motivator for citizens to participate on the Green Commuting platform. As the perceived health benefits are private value, not public value, we hypothesized that:

Hypothesis 6: Health incentives are positively related to citizens' private value acquisition when they participate on the Green Commuting platform.

Besides, the Green Commuting platform provides some IT-enabled incentives. Gamification incentives are widely used in user participation in online community, which is also used in our research case. "Gamification" is the use of game design elements in non-game contexts [17], which is a process of enhancing services with motivational factors in order to invoke gameful experiences and further behavioral outcomes $[18,19]$. A literature review that analyzed the available empirical studies on gamification concluded that gamification had predominantly positive effects on the user outcome, either psychological or behavioral 
[19]. Motivational factors of gamification most tested in empirical studies include points, leaderboards, badges, levels, story/theme, clear goal, feedback, rewards, process, and challenge, and the first three ones are the most commonly found in literatures $[19,20]$. These factors can be classified into monetary motivational factors and non-monetary ones. Monetary motivational factor refers to monetary rewards, such as monetary reward points that can be transformed into money, material goods, or paid services. Research showed that the combination of monetary reward points and gamification mechanism can increase participation probability [21]. In contrast, other motivational factors (i.e., level, leaderboards, badges, etc.) are non-monetary and related to personal images or affection within the group.

Collecting green points is a type of monetary incentives on the Green Commuting platform due to green points can be transformed into material goods or carbon points for purchasing goods in physical supermarkets. This incentive brings private benefits for citizens, which is one of selective incentives. In addition, the platform provides some non-monetary gamification incentives, such as green level and individual leaderboard based on the number of their green points. These non-monetary gamification incentives or image incentives are effective measures to encourage pro-social participation because they demonstrate participants' affection and social reputation in the group $[13,26]$. Previous studies indicated that completely offline monetary and image incentives can encourage citizen participation [26,27]. Thus, we expect that both online monetary incentives, a kind of selective incentives, and online image incentives, a type of group and expressive incentives, could attract citizens to participate on the Green Commuting platform through acquiring private value. Therefore, we hypothesized that:

Hypothesis 7: Online monetary incentives are positively related to citizens' private value acquisition when they participate on the Green Commuting platform.

Hypothesis 8: Online image incentives are positively related to citizens' private value acquisition when they participate on the Green Commuting platform.

Social-norms-derived incentives were excluded from this study because they motivated potential participants, whereas we focused on citizens who had already participated. Figure 1 presents our theoretical model.

\section{Research methodology}

Our research model was tested through a field survey of members of the Green Commuting platform in Nanjing, Jiangsu, China (see Figure 2). Actually, the platform is a functional module of MyNanjing APP. The APP was established in 2014 with the purpose of building a transparent, participatory, and sustainable governance model by using IT. The module of Green Commuting was added to the APP in 2016 in order to encourage citizens to physically take more green commuting. The platform shows times of every transportation mode (e.g., taking bus, metro and public bikes, walking and not driving private cars) a citizen has participated in one day. Citizens could proactively claim their green points as rewards after taking green commuting offline. The user homepage also provides other information, like the amount of green points, green level, and individual leaderboard of top 100. Some incentives are set on the platform, for example, green points can exchange into goods in the online mall of the platform or carbon points for purchasing goods in physical supermarkets.

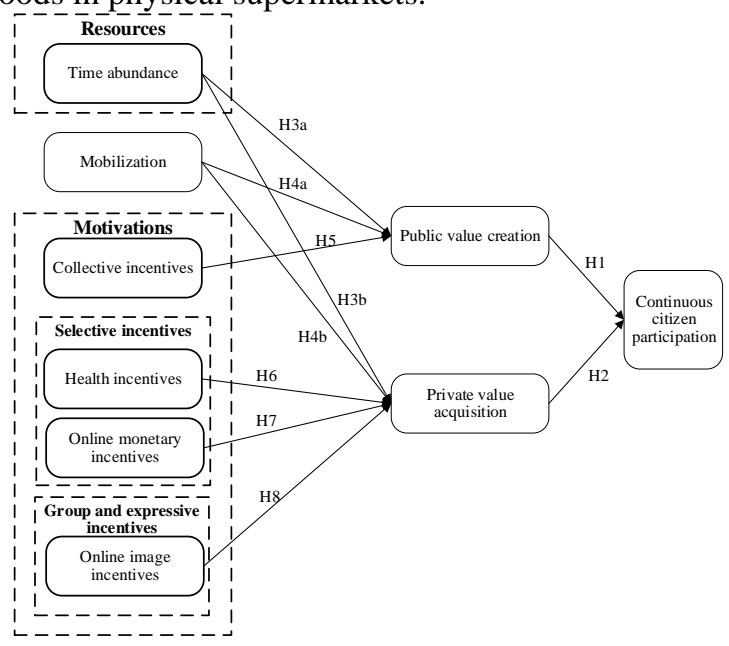

Figure 1. Research model

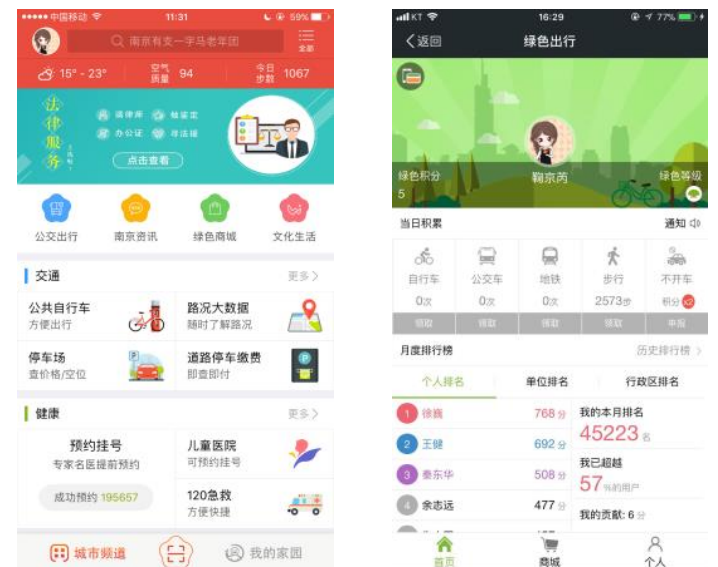

Figure 2. Homepages of the MyNanjing App and the Green Commuting module 
The survey consists of three sections. In order to ensure the validity of survey data, three questions are set up in the first section to verify whether the subject has ever used the Green Commuting platform. In the second section, subjects were asked to provide general information about their gender, education, age, and income. These are the control variables. Previous researches indicated that males have more willingness in public participation than females [29]. People who are older and with high socioeconomic status are more likely to than those with lower socioeconomic status to be politically active. Therefore, these three variants are viewed as basic socioeconomic factors to be collected in survey. The third section consisted of a set of items measured using a seven-point Likert scale, ranging from "strongly disagree" to "strongly agree". Table 1 summarizes the construct operationalization.

\section{Table 1. Constructs and measures}

\begin{tabular}{|c|c|}
\hline Construct & Measure \\
\hline $\begin{array}{l}\text { Time } \\
\text { abundance } \\
\text { (TA) }\end{array}$ & $\begin{array}{l}\text { TA1: I have enough time to participate in green commuting. } \\
\text { TA2: Time to participate in green commuting is part of my schedule. } \\
\text { TA3: I can afford the cost of time to participate in green commuting. }\end{array}$ \\
\hline $\begin{array}{l}\text { Mobilization } \\
\text { (MO) }\end{array}$ & $\begin{array}{l}\text { MO1: The engagement of people around me promotes my participation } \\
\text { in green commuting. } \\
\text { MO2: The recommendation of people around me promotes my } \\
\text { participation in green commuting. } \\
\text { MO3: The involvement of my families or friends in green commuting } \\
\text { has a positive impact on me. }\end{array}$ \\
\hline $\begin{array}{l}\text { Collective } \\
\text { incentives } \\
\text { (CI) }\end{array}$ & $\begin{array}{l}\text { C11: Participation in green commuting can make positive social effect. } \\
\text { C12: Participation in green commuting is a way to respond to } \\
\text { government call. } \\
\text { C13: Participation in green commuting can facilitate the increasement of } \\
\text { social collective benefits. }\end{array}$ \\
\hline $\begin{array}{l}\text { Health } \\
\text { benefits } \\
\text { (HB) }\end{array}$ & $\begin{array}{l}\text { HB1: Participating in green commuting is benefit for my health. } \\
\text { HB2: Participating in green commuting can make my body strong. } \\
\text { HB3: Participating in green commuting is a way to do physical exercise. }\end{array}$ \\
\hline $\begin{array}{l}\text { Online } \\
\text { monetary } \\
\text { incentives } \\
\text { (OMI) }\end{array}$ & $\begin{array}{l}\text { OMI1: The material rewards (i.e., money, prize) obtained on the Green } \\
\text { Commuting platform are attractive to me. } \\
\text { OMI2: The material rewards (i.e., money, prize) obtained on the Green } \\
\text { Commuting platform can encourage me to continuously participate in } \\
\text { green commuting. } \\
\text { OMI3: In order to acquire more material rewards (i.e., money, prize) } \\
\text { from the Green Commuting platform, I will continuously participate in } \\
\text { green commuting. }\end{array}$ \\
\hline $\begin{array}{l}\text { Online } \\
\text { image } \\
\text { incentives } \\
\text { (OII) }\end{array}$ & $\begin{array}{l}\text { OII1: Earning green points on the Green Commuting platform is } \\
\text { attractive to me. } \\
\text { OII2: I will continuously participate in green commuting to increase my } \\
\text { green points. } \\
\text { OII3: It makes me happy to earn more green points on the Green } \\
\text { Commuting platform. }\end{array}$ \\
\hline $\begin{array}{l}\text { Public value } \\
\text { creation } \\
\text { (PUVC) }\end{array}$ & $\begin{array}{l}\text { PUVC1: I would like to participate on the Green Commuting platform } \\
\text { to bring benefits for the urban traffic and environment. } \\
\text { PUVC2: I would like to participate on the Green Commuting platform } \\
\text { to bring positive changes to the urban appearance. } \\
\text { PUVC3: I would like to participate on the Green Commuting platform } \\
\text { to play a positive effect on the sustainable urban development. }\end{array}$ \\
\hline $\begin{array}{l}\text { Private } \\
\text { value } \\
\text { acquisition } \\
\text { (PRVA) }\end{array}$ & $\begin{array}{l}\text { PRVA1: I gain benefits through participating on the Green Commuting } \\
\text { platform. } \\
\text { PRVA2: I obtain something valuable through participating on the Green } \\
\text { Commuting platform. } \\
\text { PRVA3: Participating on the Green Commuting platform bring me } \\
\text { more advantages than disadvantages. }\end{array}$ \\
\hline $\begin{array}{l}\text { Continuous } \\
\text { citizen } \\
\text { participation } \\
\text { (CCP) }\end{array}$ & $\begin{array}{l}\text { CCP1: I want to continue using the Green Commuting platform rather } \\
\text { than discontinue its use. } \\
\text { CCP2: My intentions are to continue using the Green Commuting } \\
\text { platform rather than any alternative means, such as step recording Apps } \\
\text { and fitness Apps. } \\
\text { CCP3: If I could, I would like to discontinue use of the Green } \\
\text { Commuting platform. }\end{array}$ \\
\hline
\end{tabular}

Data for this study were collected using an online survey with the cooperation of Baidu Test, a professional crowdsourcing platform that randomly distributes questionnaires to 10000 citizens in Nanjing by restricting their Network IP addresses. Additionally,
Baidu Test platform applied technological means, like comparing IP address, Baidu account, and cookie, to make sure the uniqueness of subjects. Finally, we collected 269 valid questionnaires. The number of valid questionnaires is smaller than the number of distributed questionnaires because of the three verification questions. Structural equation modeling (SEM) is used in this study as it can test complex models that feature interactions and multiple-cause effects to simultaneously confirm the theoretical hypotheses through analysis of empirical data. SmartPLS software was used to analyze our data in this study.

\section{Data analysis and results 4.1. Measurement model analysis}

The reliability and convergent validity were assessed for the measures. The results are presented in Table 2. Specifically, Table 2 shows the descriptive statistics, Cronbach's alpha (CA), composite reliability (CR), and average variance extracted (AVE) of the constructs [30]. It can be seen that all constructs exhibited acceptable convergent validity, i.e., $\mathrm{CA}>0.7, \mathrm{CR}>0.7$, and AVE $>0.5$.

The constructs also demonstrated acceptable discriminant validity. First, discriminant validity is assessed by comparing the square root of AVE of each construct against its correlations with other constructs [30]. Table 2 shows that diagonal elements (square root of AVE) are larger than other entries in the same row or column (correlations with other constructs), thus satisfying the validity requirement. Second, the factor loadings of all items on their respective constructs are significantly high (all $>0.8$, above the minimum recommended level of 0.5) [31]. Moreover, all measurement items loaded more on its theoretically assigned construct than any construct other constructs. These two criteria indicate that all constructs share more variance with their measurement items than with another construct.

Table 2. Result of the reliability and validity

\begin{tabular}{|c|c|c|c|c|c|c|c|c|c|c|}
\hline \multicolumn{11}{|c|}{ analysis } \\
\hline & & TA & $\mathrm{CCP}$ & $\mathrm{CI}$ & $\mathrm{HI}$ & $\mathrm{MO}$ & OII & $\begin{array}{l}\text { OM } \\
\mathrm{I} \\
\end{array}$ & $\begin{array}{l}\text { PR } \\
\text { VA }\end{array}$ & $\begin{array}{l}\text { PU } \\
\text { VC }\end{array}$ \\
\hline TA & & 0.92 & & & & & & & & \\
\hline СCP & & 0.67 & 0.87 & & & & & & & \\
\hline CI & & 0.73 & 0.66 & 0.89 & & & & & & \\
\hline HI & & 0.70 & 0.69 & 0.79 & 0.89 & & & & & \\
\hline MO & & 0.71 & 0.75 & 0.76 & 0.73 & 0.91 & & & & \\
\hline OII & & 0.64 & 0.77 & 0.63 & 0.68 & 0.77 & 0.89 & & & \\
\hline OMI & & 0.55 & 0.61 & 0.56 & 0.57 & 0.70 & 0.79 & 0.89 & & \\
\hline PRVA & & 0.68 & 0.83 & 0.74 & 0.80 & 0.74 & 0.69 & 0.54 & 0.89 & \\
\hline PUVC & & 0.66 & 0.71 & 0.78 & 0.80 & 0.67 & 0.65 & 0.59 & 0.77 & 0.89 \\
\hline $\mathrm{CA}$ & & 0.90 & 0.84 & 0.87 & 0.87 & 0.89 & 0.87 & 0.88 & 0.87 & 0.87 \\
\hline $\mathrm{CR}$ & & 0.94 & 0.91 & 0.93 & 0.92 & 0.93 & 0.92 & 0.92 & 0.92 & 0.92 \\
\hline AVE & & 0.84 & 0.76 & 0.79 & 0.79 & 0.82 & 0.79 & 0.80 & 0.79 & 0.80 \\
\hline \multirow{3}{*}{$\begin{array}{c}\text { Factor } \\
\text { loading }\end{array}$} & $\begin{array}{c}\text { Item } \\
1\end{array}$ & 0.92 & 0.89 & 0.90 & 0.90 & 0.92 & 0.89 & 0.90 & 0.90 & 0.89 \\
\hline & $\begin{array}{c}\text { Item } \\
2\end{array}$ & 0.91 & 0.85 & 0.88 & 0.90 & 0.88 & 0.89 & 0.90 & 0.89 & 0.90 \\
\hline & $\begin{array}{c}\text { Item } \\
3\end{array}$ & 0.91 & 0.87 & 0.90 & 0.88 & 0.90 & 0.88 & 0.88 & 0.88 & 0.89 \\
\hline
\end{tabular}




\subsection{Structural model analysis}

The first test on the structural model to predict the hypotheses is the coefficient of determination, $\mathrm{R}^{2}$. Its values should be sufficiently high for the model to have a minimum level of explanatory power. The results are presented in Table 3 and Figure 3. It can be seen that all the exogenous factors in the model respectively explained $63 \%$ and $71 \%$ of the variation of public value creation and private value acquisition. Public value creation and private value acquisition explained $70 \%$ of continuous citizen participation. From the above figures, intention to use did not adequately explain actual use. According to Chin, $\mathrm{R}^{2}$ values above 0.63 are substantial [24].

The second assessment for the structural model is the path coefficient that shows the degree of relationship between constructs. Table 3 displays all the hypothesized paths in our research model, including the path coefficients and $\mathrm{T}$-values that access the significance of the paths. According to four significance levels, nine path coefficients are statistically significant, which means that nine of ten hypotheses were supported. Specifically, both public value creation and private value acquisition significantly motivate citizens to continuously participate on the Green Commuting platform (H1 and $\mathrm{H} 2$ were supported). Time abundance is a significant predictor of public value creation (H3a was supported) but a weak significant predictor (significant at 0.1 level) of private value acquisition (H3b was weakly supported). In contrast, mobilization has a more significant effect on private value acquisition (H4b was supported) than public value creation (H4a was weakly supported). Collective incentive is a significant predictor of public value creation (H5 was supported). For the other three incentives, health incentives and online image incentive are significant predictors of private value acquisition (H6 and $\mathrm{H} 8$ were supported), but online monetary incentive is not. Additionally, all control variables have non-significant effects on continuous citizen participation.

\section{Table 3. Results of the hypotheses testing}

\begin{tabular}{|c|c|c|c|}
\hline Hypothesis & $\begin{array}{l}\text { Path coeff. } \\
\text { (std. error) }\end{array}$ & T-test & $\begin{array}{c}\text { Hypothesis testing } \\
\text { result }\end{array}$ \\
\hline H1: PUVC to CCP & $0.18(0.06)$ & $2.71 * *$ & Supported \\
\hline $\mathrm{H} 2$ : PRVA to CCP & $0.70(0.06)$ & $12.09 * * *$ & Supported \\
\hline H3a: TA to PUVC & $0.16(0.08)$ & $2.03 *$ & Supported \\
\hline H3b: TA to PRVA & $0.12(0.06)$ & $1.89^{+}$ & Weakly supported \\
\hline H4a: MO to PUVC & $0.13(0.08)$ & $1.67^{+}$ & Weakly supported \\
\hline H4b: MO to PRVA & $0.22(0.07)$ & $3.12 * *$ & Supported \\
\hline H5: CI to PUVC & $0.56(0.08)$ & $6.87 * * *$ & Supported \\
\hline H6: HI to PRVA & $0.48(0.07)$ & $7.24 * * *$ & Supported \\
\hline H7: OMI to PRVA & $-0.10(0.07)$ & 1.47 & Not supported \\
\hline H8: OII to PRVA & $0.20(0.07)$ & $2.68 * *$ & Supported \\
\hline
\end{tabular}

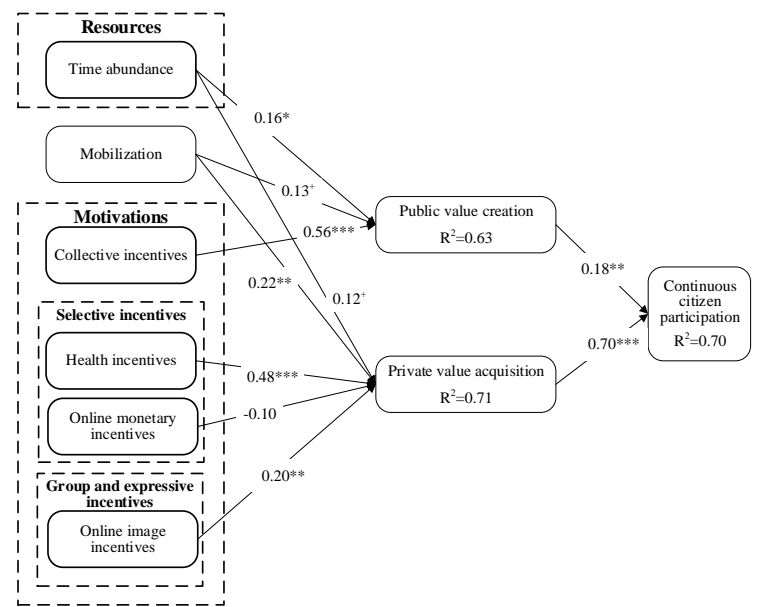

Figure 3. Structural model results

\subsection{Post-hoc assessments of the mediating effects}

To further confirm the roles of public value creation and private value acquisition during participation, we perform tests of mediation for all possible paths from antecedents to continuous citizen participation to verify whether additional direct paths, not specified in the hypothesized model, might be significant. Mediation analyses are most often guided by Baron and Kenny' mediation test procedures and Sobel's test $[25,49]$. The assumption of the Sobel test is that the distribution of the products of coefficients (ab) follows a normal distribution under the null hypothesis. As the distribution of products is usually positively skewed, bootstrapping, an alternative approach, was proposed to bootstrap the sampling distribution of ab [48,52], which is well-suited for testing our mediators because it relies on bootstrapping and, therefore, does not require large sample sizes and our indirect effect estimation involving product of terms tends to have a skewed sampling distribution. A decision tree and a step-by-step procedure for testing mediation proposed by Zhao et al. integrated bootstrapping into the third step of Baron and Kenny' procedure to compute the significance of indirect effect [48], which were employed in our mediation effect analysis.

Table 4 shows the results for the tests of mediation. For instance, we add the path from time abundance to continuous citizen participation in a three-variable causal model, TA-PUVC-CCP. Firstly, we examined that time abundance (the independent variable (IV)) has a significant effect on continuous citizen participation (the dependent variable (DV)) without involving public value creation (the mediating variable (MV)). Second, there was a significant effect of time abundance (IV) on public value creation (MV). Third, there was a significant effect of public value creation 
(MV) on continuous citizen participation (DV) and the effect of time abundance (IV) on continuous citizen participation (DV) was reduced. According to the decision tree (Zhao et al., 2010), time abundance is acting as a complementary mediator and is likely an omitted mediator.

Further, we used the Bootstrapping method of SmartPLS software to obtain 5000 sets of a path coefficient value and $b$ path coefficient value and then we estimated the indirect effects through calculating the average of the product of two path coefficients. To derive the $99 \%$ confidence interval (CI), the products of 5000 estimates of ab were sorted from low to high. The lower limit and upper limit of the CI were defined as the 25th and 4976th scores. Coefficient estimates of the indirect effects were statistically significantly when the CI does not include 0 [48,52]. The result showed that the indirect effect of time abundance on continuous citizen participation through public value creation was positive and significant (indirect effect: 0.311 ; bias corrected $99 \%$ CI: 0.183, 0.447, not including 0 ). Therefore, the mediation effect of public value creation received support. Additionally, we calculated the variance accounted for (VAF) to present the relative size of the mediating effect. The result (VAF=0.464) was the average of the 5000 VAFs. Other mediation hypotheses were examined and received supports following the same procedure.

Table 4. Mediation analysis results

\begin{tabular}{|c|c|c|c|c|c|c|c|c|c|}
\hline \multirow{3}{*}{ IV-MV-DV } & \multicolumn{4}{|c|}{ Baron and Kenny } & \multicolumn{5}{|c|}{ Bootstrapping (Sample=5000) } \\
\hline & \multirow[t]{2}{*}{ Step $1: c$} & \multirow[t]{2}{*}{ Step 2:a } & \multicolumn{2}{|c|}{ Step 3: } & \multirow{2}{*}{$\begin{array}{l}\text { Indirect } \\
\text { effect }\end{array}$} & \multicolumn{2}{|c|}{$\begin{array}{l}\text { Bias corrected } \\
99 \% \mathrm{Cl} \text { for } \\
\text { indirect effect }\end{array}$} & \multirow[t]{2}{*}{ Significance } & \multirow[t]{2}{*}{ VAF } \\
\hline & & & b & $\mathrm{c}^{\prime}$ & & Lower & Upper & & \\
\hline TA-PUVC-CCP & $0.67^{* * * * *}$ & $0.66^{* * * * *}$ & $0.47 * * *$ & $0.36^{* * * *}$ & 0.31 & 0.18 & 0.45 & Yes & 0.46 \\
\hline TA-PRVA-CCP & $0.67^{* * * * *}$ & $0.68^{* * * * *}$ & $0.69 * * *$ & $0.20^{* * * *}$ & 0.47 & 0.34 & 0.6 & Yes & 0.7 \\
\hline MO-PUVC-CCP & $0.75^{* * * * *}$ & $0.67^{* * * * *}$ & $0.37 * * *$ & $0.50^{* * * *}$ & 0.25 & 0.13 & 0.39 & Yes & 0.34 \\
\hline MO-PRVA-CCP & $0.75^{* * * * *}$ & $0.74^{* * * * *}$ & $0.61 * * *$ & $0.31^{* * * * *}$ & 0.44 & 0.33 & 0.58 & Yes & 0.59 \\
\hline CI-PUVC-CCP & 0.66 **** & $0.78^{* * * * *}$ & $0.49 * * *$ & $0.28 * *$ & 0.38 & 0.2 & 0.58 & Yes & 0.58 \\
\hline HI-PRVA-CCP & $0.69^{* * * * *}$ & $0.80^{\text {****** }}$ & $0.77^{*} * * *$ & 0.08 & 0.61 & 0.47 & 0.76 & Yes & 0.88 \\
\hline OII-PRVA-CCP & 0.77 **** & $0.69 * * *$ & $0.57 * * *$ & $0.38^{* * * *}$ & 0.39 & 0.28 & 0.51 & Yes & 0.51 \\
\hline
\end{tabular}

\section{Discussion and conclusions}

This research proposed a more comprehensive citizen participation model by extending the CVM with the general incentives model and some related ITenabled incentives and drawn on the social exchange perspective to theorize the roles of pubic value creation and private value acquisition between antecedents of participation and continuous participation behavior. The model was examined in the context of citizen participation in IT-enabled green commuting. It was well supported empirically, with only one hypothesis being not supported. The mediation analysis showed that both public value creation and private value acquisition have significant mediating effects on the relationship between its antecedent and citizen participation.

This study has some theoretical contributions. First, we contribute toward a more holistic theory of participation in social activities by deriving participation antecedents from the CVM [12] and related incentive models [13] and integrating them with the IT-related factors from the perspective of gamification [17]. Specifically, although the CVM proposes participation antecedent in terms of motivation, and the motivation has been extended by the general incentives model and empirically tested in online political participation [9], it limits its attention to IT-enabled motivations, e.g., gamification incentives. We identified two categories of gamification incentives, online monetary incentives and online image incentives. According to our analysis, online image incentives can be served as an effective antecedent that could promote private value acquisition but online monetary incentives cannot. Actually, there has been no consistent results for the roles of offline monetary incentives on citizen participation [26,37]. Some studies figured out that participant may shift an individual's decision frame from a social frame to a monetary frame when monetary incentives make effects in the participation process, which destroys one's internal incentives, and thus makes an insignificant effect or even a significant negative effect on participation [26,57,51].

Second, our research distinguishes public value and private value simultaneously generated by citizen participation [7,32,33,56]. Our research advances previous literature $[8,9,50]$ by systematically theorizing and validating the different participation antecedents of public value creation versus private value acquisition. Particularly, previous literature hasn't focused on the mechanism of antecedents on participation and all antecedents haven't been distinguished according to their driving forces on values in different orientation, e.g., public value for public sectors is a negative value for citizens, and private value for themselves is a positive value instead. Our study finds that public value creation can be motivated by time abundance, mobilization, and collective incentives and private value acquisition can be motivated by time abundance, mobilization, health incentives, and online image incentives. Additionally, private value acquisition has nearly four times greater effect on facilitating citizen continuously to participate in social activities than public value creation, which brings new insights for the importance of private value in the process of citizen participation.

Third, this study extends our understanding of what derives participation in IT-enabled social activities where participants provide contribution to social 
benefits as well as gain personal benefits. Specifically, motivations in CVM play a more important role than resource and mobilization. According to the value of path coefficients in Figure 3, collective incentives in the dimension of motivation has much greater force on facilitating public value creation than time abundance and mobilization, and health incentive in the dimension of motivation also has a much greater force on facilitating private value acquisition than other antecedents.

Our study has three implications. First, managers of public sectors need to focus on the antecedents that motivate private value acquisition because private value acquisition has much greater effect on promoting citizen participation than public value creation. Secondly, public sectors should put more effort in advocating the benefits for health that produced by physical participation in the green commuting because health incentives have the greatest influence on private value acquisition than other actors. Third, public sectors could spend less efforts on designing and implementing more online monetary incentives because online monetary incentives don't have significant effect on private value acquisition that enhances the probability of citizen participation.

However, the limitations of the study need to be recognized. Our study is conducted in a city-level green commuting platform. As the contexts with regards to traffic and environment vary across cities, the internal motivations for participation may be affected. Future research may investigate green commuting platform in other cities or nations to further validate our findings. Additionally, the proposed participation model and results need to be widely examined by more cases, which may bring more new insights.

\section{Acknowledgements}

This research was supported by the National Natural Science Foundation of China [91646105, 71781220619, 71429001, 71472053]; the Postdoctoral Science Foundation of China [2014M550198, 2015T80363]; and the China Scholarship Council [201706120223, 201706125025].

\section{References}

[1] Moore $\mathrm{M}$ H. Creating public value: Strategic management in government[M]. Harvard university press, 1995.

[2] Benington J, Moore M H. Public value in complex and changing times[J]. Public value: Theory and practice, 2011: $1-30$.

[3] Stoker G. Public value management: A new narrative for networked governance?[J]. The American review of public administration, 2006, 36(1): 41-57.
[4] Bryson J M, Crosby B C, Bloomberg L. Public value governance: Moving beyond traditional public administration and the new public management[J]. Public Administration Review, 2014, 74(4): 445-456.

[5] Voorberg W H, Bekkers V J J M, Tummers L G. A systematic review of co-creation and co-production: Embarking on the social innovation journey[J]. Public Management Review, 2015, 17(9): 1333-1357.

[6] Green D, Shapiro I. Pathologies of rational choice theory: A critique of applications in political science[M]. Yale University Press, 1996.

[7] Alford J. Defining the client in the public sector: A social - exchange perspective[J]. Public administration review, 2002, 62(3): 337-346.

[8] Phang C W, Kankanhalli A, Huang L. Drivers of quantity and quality of participation in online policy deliberation forums[J]. Journal of Management Information Systems, 2014, 31(3): 172-212.

[9] Phang C W, Kankanhalli A, Tan B C Y. What motivates contributors vs. lurkers? An investigation of online feedback forums[J]. Information Systems Research, 2015, 26(4): 773792.

[10] Pattie C, Seyd P, Whiteley P. Citizenship and civic engagement: Attitudes and behaviour in Britain[J]. Political Studies, 2003, 51(3): 443-468.

[11] Seyd P, Whiteley P, Pattie C. Citizenship in Britain: attitudes and behaviour[J]. The Political Quarterly, 2001, 72(s1): 141-148.

[12] Verba S, Schlozman K L, Brady H E. Voice and equality: Civic voluntarism in American politics[M]. Harvard University Press, 1995.

[13] Seyd P, Whiteley P. New Labour's grassroots: The transformation of the Labour Party membership[M]. Springer, 2002.

[14] Snow D A, Rochford Jr E B, Worden S K, et al. Frame alignment processes, micromobilization, and movement participation[J]. American sociological review, 1986: 464481.

[15] Putnam R D, Leonardi R, Nanetti R Y. Making democracy work: Civic traditions in modern Italy[M]. Princeton university press, 1994.

[16] Olson M. The Logic of Collective Action: Public Goods and the Theory of Groups, Second printing with new preface and appendix[M]. Harvard University Press, 2009.

[17] Deterding S, Dixon D, Khaled R, et al. From game design elements to gamefulness: defining gamification[C]//Proceedings of the 15 th international academic MindTrek conference: Envisioning future media environments. ACM, 2011: 9-15.

[18] Hamari J. Transforming homo economicus into homo ludens: A field experiment on gamification in a utilitarian peer-to-peer trading service[J]. Electronic commerce research and applications, 2013, 12(4): 236-245.

[19] Huotari K, Hamari J. Defining gamification: a service marketing perspective[C]//Proceeding of the 16th international academic MindTrek conference. ACM, 2012: $17-22$.

[20] Xu Y. Literature review on web application gamification and analytics[J]. Honolulu, HI, 2011: 11-05.

[21] Ueyama Y, Tamai M, Arakawa Y, et al. Gamificationbased incentive mechanism for participatory 
sensing $[\mathrm{C}] / /$ Pervasive Computing and Communications Workshops (PERCOM Workshops), 2014 IEEE International Conference on. IEEE, 2014: 98-103.

[22] Schwartz S H, Bardi A. Value hierarchies across cultures: Taking a similarities perspective[J]. Journal of cross-cultural Psychology, 2001, 32(3): 268-290.

[23] Bardi A, Schwartz S H. Values and behavior: Strength and structure of relations[J]. Personality and social psychology bulletin, 2003, 29(10): 1207-1220.

[24] Chin W W. The partial least squares approach to structural equation modeling $[\mathrm{J}]$. Modern methods for business research, 1998, 295(2): 295-336.

[25] Sobel M E. Asymptotic confidence intervals for indirect effects in structural equation models[J]. Sociological methodology, 1982, 13: 290-312.

[26] Ariely D, Bracha A, Meier S. Doing good or doing well? Image motivation and monetary incentives in behaving prosocially[J]. American Economic Review, 2009, 99(1): 544-55.

[27] Bucciol A, Montinari N, Piovesan M. Do not trash the incentive! Monetary incentives and waste sorting[J]. The Scandinavian Journal of Economics, 2015, 117(4): 12041229.

[28] Mergel I. Distributed democracy: Seeclickfix. com for crowdsourced issue reporting[J]. 2012.

[29] Susan H. Gender and Democracy in Computer-Mediated Communication[J]. Computerisation and Controversy: Value Conflicts and Social Choices, 2nd ed,(San Diego, Academic Press). Google Scholar, 1996.

[30] MacKenzie S B, Podsakoff P M, Podsakoff N P. Construct measurement and validation procedures in MIS and behavioral research: Integrating new and existing techniques[J]. MIS quarterly, 2011, 35(2): 293-334.

[31] Murtagh F, Heck A. Multivariate data analysis[M]. Springer Science \& Business Media, 2012.

[32] Sancino A. The meta co-production of community outcomes: Towards a citizens' capabilities approach[J]. VOLUNTAS: International Journal of Voluntary and Nonprofit Organizations, 2016, 27(1): 409-424.

[33] Nabatchi T, Sancino A, Sicilia M. Varieties of participation in public services: The who, when, and what of coproduction[J]. Public Administration Review, 2017, 77(5): 766-776.

[34] Seyd P, Whiteley P, Pattie C. Citizenship in Britain: attitudes and behaviour[J]. The Political Quarterly, 2001, 72(s1): 141-148.

[35] Verba S, Nie N H. Participation in America: Political democracy and social equality[M]. University of Chicago Press, 1987.

[36] Dubé J P, Luo X, Fang Z. Self-signaling and prosocial behavior: A cause marketing experiment[J]. Marketing Science, 2017, 36(2): 161-186.

[37] Ashraf N, Bandiera O, Jack B K. No margin, no mission? A field experiment on incentives for public service delivery[J]. Journal of Public Economics, 2014, 120: 1-17.

[38] Williams I, Shearer H. Appraising public value: Past, present and futures[J]. public administration, 2011, 89(4): 1367-1384.

[39] Cordella A, Bonina C M. A public value perspective for ICT enabled public sector reforms: A theoretical reflection[J]. Government information quarterly, 2012, 29(4): 512-520.
[40] Bannister F, Connolly R. ICT, public values and transformative government: A framework and programme for research[J]. Government Information Quarterly, 2014, 31(1): 119-128.

[41] Klievink B, Bharosa N, Tan Y H. The collaborative realization of public values and business goals: Governance and infrastructure of public-private information platforms[J]. Government Information Quarterly, 2016, 33(1): 67-79.

[42] Beaumont E. Promoting political agency, addressing political inequality: A multilevel model of internal political efficacy[J]. The Journal of Politics, 2011, 73(1): 216-231.

[43] Hansen J M. The political economy of group membership[J]. American Political Science Review, 1985, 79(1): 79-96.

[44] Kenny C B. Political participation and effects from the social environment[J]. American Journal of Political Science, 1992: 259-267.

[45] Rosenstone S J, Hansen J. Mobilization, participation, and democracy in America[M]. Macmillan Publishing Company,, 1993.

[46] Peddibhotla N B, Subramani M R. Contributing to public document repositories: A critical mass theory perspective[J]. Organization Studies, 2007, 28(3): 327-346.

[47] Shephard R J. Is active commuting the answer to population health?[J]. Sports Medicine, 2008, 38(9): 751-758. [48] Zhao X, Lynch Jr J G, Chen Q. Reconsidering Baron and Kenny: Myths and truths about mediation analysis[J]. Journal of consumer research, 2010, 37(2): 197-206.

[49] Baron R M, Kenny D A. The moderator-mediator variable distinction in social psychological research: Conceptual, strategic, and statistical considerations $[\mathrm{J}]$. Journal of personality and social psychology, 1986, 51(6): 1173.

[50] Oni A A, Oni S, Mbarika V, et al. Empirical study of user acceptance of online political participation: Integrating Civic Voluntarism Model and Theory of Reasoned Action[J]. Government Information Quarterly, 2017, 34(2): 317-328.

[51] Andreoni J, Petrie R. Public goods experiments without confidentiality: a glimpse into fund-raising[J]. Journal of public Economics, 2004, 88(7-8): 1605-1623.

[52] Preacher K J, Hayes A F. SPSS and SAS procedures for estimating indirect effects in simple mediation models $[\mathrm{J}]$. Behavior research methods, instruments, \& computers, 2004, 36(4): 717-731.

[53] Kahn W A. Psychological conditions of personal engagement and disengagement at work $[\mathrm{J}]$. Academy of management journal, 1990, 33(4): 692-724.

[54] Kahn W A. To be fully there: Psychological presence at work[J]. Human relations, 1992, 45(4): 321-349.

[55] Nabatchi T, Steen T, Sicilia M, et al. Understanding the diversity of coproduction: introduction to the IJPA special issue[J]. International Journal of Public Administration, 2016, 39(13): 1001-1005.

[56] Osborne S P, Radnor Z, Nasi G. A new theory for public service management? Toward a (public) service-dominant approach $[\mathrm{J}]$. The American Review of Public Administration, 2013, 43(2): 135-158.

[57] Lawler J J. Not just for the money: An economic theory of personal motivation[J]. Personnel Psychology, 1998, 51(3): 740 . 